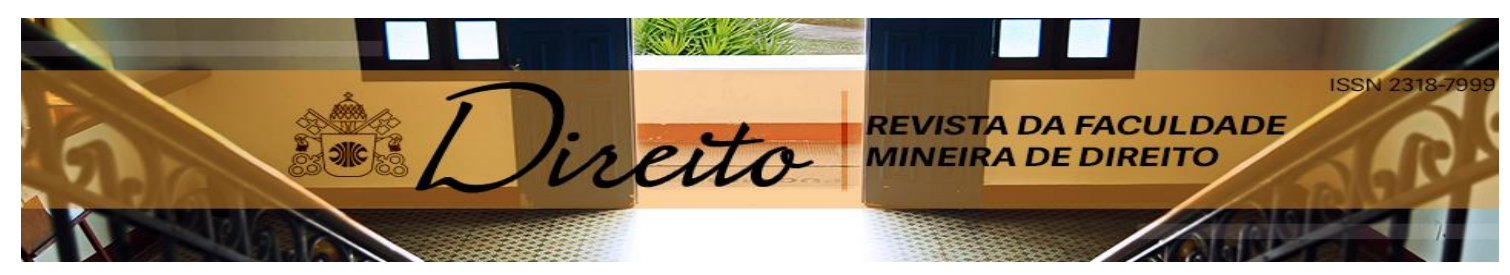

\title{
DEMOCRATIZAÇÃO DOS MEIOS DE COMUNICAÇÃO: CAMINHOS PARA A CONCRETIZAÇÃO DO DIREITO À COMUNICAÇÃO
}

\author{
LA DEMOCRATIZACIÓN DE LOS MEDIOS DE COMUNICACIÓN: \\ CAMINOS PARA LA REALIZACIÓN DEL DERECHO A LA COMUNICACIÓN \\ Cláudio Henrique Urbanavicius Jodar ${ }^{1}$ \\ Cláudia Mansani Queda de Toledo ${ }^{2}$
}

\begin{abstract}
Resumo
A liberdade de expressão e o direito de informar e informar-se são essenciais para a constituição da cidadania e a efetivação dos demais direitos fundamentais. Os meios de comunicação de massa alçaram esses direitos a um novo patamar, a ponto de já se cogitar um direito autônomo à comunicação, por se embrenharem em todos os lares, possuindo enorme poder para incutir opiniões na consciência social. A conformação da mídia brasileira, dominada por grandes conglomerados econômicos e grupos políticos, não permite, contudo, o efetivo intercâmbio de ideias. É imprescindível debater abertamente a necessidade de um novo marco regulatório, que promova a democratização dos meios de comunicação em nosso país, abandonando os discursos que tentam manter a concentração de poder sob o argumento oportunista de que qualquer controle seria sinônimo de censura.
\end{abstract}

Palavras-Chave: Direito à comunicação. Mídia. Democratização. Marco regulatório.

\begin{abstract}
La libertad de expresión y el derecho a informar y ser informado son esenciales para la formación de la ciudadanía y el ejercicio de otros derechos fundamentales. Los medios de comunicación de masa plantearam esos derechos a un nuevo nivel, a punto que ya surgir un derecho autónomo a la comunicación, porque enclavado en todos los hogares, tenendo un enorme poder para inculcar opiniones en la conciencia social. La conformación de los medios de comunicación de Brasil, dominada por las grandes corporaciones y los grupos políticos, no obstante, no permite el intercambio efectivo de ideas. Es imperativo hablar abiertamente de la necesidad de un nuevo marco regulatorio que promueva la democratización de los medios de comunicación en nuestro país, abandonando los discursos que tratan de mantener la concentración de poder bajo el argumento oportunista que cualquier control sería sinónimo de censura.
\end{abstract}

Key-words: Derecho a la comunicación. Media. Democratización. Marco regulatorio.

Artigo recebido em 03 de setembro de 2016 e aprovado em 11 de novembro de 2016 .

${ }^{1}$ Mestrando em Direito Constitucional pela Faculdade de Direito do Sul de Minas, Pouso

Alegre, Minas Gerais, Brasil.

2 Doutoranda em Sistema Constitucional de Garantia de Direitos. Professora Faculdade de Direito do Sul de Minas, Pouso Alegre, Minas Gerais, Brasil. 


\section{INTRODUÇÃo}

O homem é, por natureza, um ser comunicacional, que se sente impelido a compartilhar suas ideias com os demais e escutar aquelas de seus semelhantes, formando sua opinião sobre os temas que reputa relevantes a partir desse amálgama. $\mathrm{O}$ avanço dos meios de comunicação ampliou eminentemente a possibilidade de disseminação das informações, alçando esse traço natural dos seres humanos a patamares diferenciados.

No entanto, o crescimento da mídia em nosso país não foi acompanhado uma efetiva preocupação com a pluralidade e o intercâmbio de ideias. O sistema capitalista apropriou-se dos meios de comunicação, transformando-os em mercadorias e estabelecendo o primado máximo do lucro. Os programas e conteúdos são escolhidos prioritariamente de acordo com os índices de audiência e o interesses dos anuciantes.

É imprescindível que a sociedade recorde-se que a radiodifusão é um serviço público, exercido pelos particulares apenas a título de concessão, devendo primar pelo atendimento dos princípios estatuídos no artigo 221 da Constituição Federal. Não podem mais ser tolerados os discursos disseminados pelos grandes oligopólios da mídia, que procuram equiparar qualquer discussão sobre regulamentação com censura ou cerceio à liberdade de imprensa.

O objetivo do presente artigo é justamente esquadrinhar a realidade que marca os meios de comunicação em nosso país, enfatizar a necessidade e a licitude da adoção de marcos regulatórios para esse setor e apresentar propostas concretas que contribuam para a reflexão e a discussão acerca dos caminhos que devem ser trilhados para a sua democratização.

Além da pesquisa de referências bibliográficas e dados estatísticos, serão delineados os principais dispositivos de diplomas internacionais que tratam da liberdade de expressão e dos direitos à informação e à comunicação, com o intuito de demonstrar a importância e os efetivos contornos desses direitos.

Serão analisados, ainda, os esforços despendidos em outros países, de forma a comprovar que existem alternativas para a configuração da mídia e que a sua implementação pode trazer efeitos benéficos, que são simplesmente omitidos nas ponderações apresentadas levianamente pelos veículos de comunicação que vicejam no Brasil.

\section{LIBERDADE DE EXPRESSÃO E DIREITOS À INFORMAÇÃO E COMUNICAÇÃO}

A discussão sobre a necessidade de democratização dos meios de comunicação exige uma breve digressão sobre as liberdades de expressão e os direitos à informação e comunicação, de forma a desconstruir o discurso que tem sido deliberadamente invocado pelos grandes conglomerados midiáticos para impedir qualquer tipo de regulamentação específica sobre o setor.

A liberdade de expressão surgiu sob o jugo das teorias jusnaturalistas individualistas, que concebiam os homens como seres dotados de direitos imanentes, que deveriam ser 
necessariamente respeitados pelo Estado ${ }^{1}$. O artigo 11 da Declaração dos Direitos do Homem e do Cidadão, aprovada pela Assembleia Nacional Francesa em 26 de agosto de 1789, previa que

\begin{abstract}
"a livre comunicação das ideias e das opiniões é um dos mais preciosos direitos do homem, todo cidadão pode, portanto, falar, escrever, imprimir livremente, respondendo, todavia, pelos abusos desta liberdade nos termos previstos em lei".
\end{abstract}

Ainda que tal declaração tenha sido publicada em momento histórico em que se clamava fortemente pela liberdade, já se delineava nesse artigo que não se tratava de uma liberdade absoluta, mas sim um direito que poderia ser limitado com o intuito de evitar a ocorrência de abusos.

Hegel também alertava que a liberdade de expressão não poderia ser tratada sem restrições no âmbito do Estado, não podendo o indivíduo agir de forma descomedida e descompromissada, sob pena de resvalar para o $a^{b} u_{s o}{ }^{2}$. Certamente, o filósofo não imaginava nessa época as enormes dimensões dos atuais meios de comunicação de massa, com poderes para influenciar e moldar a opinião pública de acordo com seus interesses particulares e privados.

Paulatinamente, a liberdade de expressão revelou-se limitada, pois não abrangia o direito dos homens a acessarem dados relevantes para a formação de suas opiniões. Emergiu então o direito à informação, vislumbrado sob as óticas ativa e passiva, desdobrando-se nos direitos de informar e de ser informado ${ }^{3}$. Essa concepção pode ser extraída do artigo 19 da Declaração Universal dos Direitos Humanos, proclamada pela Assembleia Geral das Nações Unidas em 10 de dezembro de 1948, ao dispor que

"toda pessoa tem direito à liberdade de opinião e expressão; este direito inclui a liberdade de, sem interferência, ter opiniões e de procurar, receber e transmitir informações e ideias por quaisquer meios e independentemente de fronteiras".

1 BOBBIO, Norberto. A Era dos Direitos. Rio de Janeiro: Editora Elsevier, 2004, p. 50 e 51.

NOVELLI, Pedro Geraldo Aparecido. A Questão da Liberdade de Expressão em Hegel. Disponível em: <http://www.uece.br/kalagatos/dmdocuments/A-questao-da-liberdade-deexpressao-em-Hegel.pdf>. Acesso em: 02 de julho de 2014.

3 FARIAS, Edilsom Pereira de. Liberdade de Expressão e Comunicação: Teoria e proteção constitucional. Tese de Doutorado. Universidade Federal de Santa Catarina, Florianópolis, 2001, p. 74. 
$\mathrm{Na}$ década de 70, o avanço das tecnologias da informação e sua progressiva concentração impuseram novos desafios a esses direitos, pois tornou-se cada vez mais evidente que a dominação dos meios de comunicação implicava em um modelo vertical de fluxo unilateral de informações. O reconhecimento da interdependência e da necessidade de diálogo entre as culturas constituiu a base sobre a qual se estruturou o conceito de direito humano à comunicação ${ }^{4}$.

A liberdade de expressão e o direito à informação continuam desempenhando papel central, mas o direito à comunicação emergiu como uma ferramenta para a sua concretização diante da conformação atual da mídia, garantindo que todos os cidadãos possam ser ouvidos e considerados em suas opiniões. Esse direito está necessariamente atrelado ao diálogo entre iguais, com exclusão de toda relação de poder e dominação, conceitos essenciais para o debate da democratização dos meios de comunicação.

\section{PERFIL DOS MEIOS DE COMUNICAÇÃO NO BRASIL}

No Brasil, os meios de comunicação estão concentrados nas mãos de uma pequena parcela da sociedade com condições econômicas privilegiadas, que os utilizam deliberadamente com o intuito de ampliar a sua influência sobre os demais cidadãos, disseminando sorrateiramente ideias que favorecem a sua manutenção no poder.

Marilena Chauí ${ }^{5}$ tem sido um das principais expoentes a destacar o poder exercido pelos meios de comunicação, que é concretizado sob a forma do que a autora denomina de ideologia da competência, segundo a qual não é qualquer um que pode dizer qualquer coisa acerca do outro. Somente aqueles que são nominados como competentes sabem e por isso tem condições de ensinar àqueles que não detém o conhecimento.

A atuação da Sociedade Interamericana de Imprensa - SIP tem sido um exemplo claro da estreita relação entre os proprietários dos meios de comunicação e os interesses econômicos subjacentes. Ao lermos o nome dessa sociedade, poderíamos imaginar que se trata de uma agremiação de jornalistas, reunidos com o intuito de discutir os grandes desafios mundiais enfrentados pela imprensa. Corresponde, contudo, a uma entidade internacional que congrega apenas proprietários e editores de jornais e revistas.

Essa organização foi arquitetada em 1926, durante o Congresso Panamericano de Imprensa e constituída em 1943, na Cuba de Fulgêncio Batista. Os proprietários dos veículos de comunicação dos Estados Unidos assumiram seu comando em 1945 e alteraram em 1950 o

4 MATTELART, Armand. A Construção Social do Direito à Comunicação como parte integrante dos Direitos Humanos. Intercom - Revista Brasileira de Ciências da Comunicação, São Paulo, v. 32, № I, jan./jun. de 2009, p. 38.

5 CHAUÍ, Marilena. Poder da Mídia. Disponível em: <http://www.paraexpressaraliberdade.org.br/index.php/noticias/80-chaui-integral>. Acesso em: 04 de julho de 2014. 
critério de sufrágio, passando o voto a ser por jornal e não por país. A partir de então as empresas norte-americanas passaram a ter a hegemonia dessa entidade ${ }^{6}$.

Ao ingressamos no site da Sociedade Interamericana de Imprensa, essa entidade apresenta-se como uma organização sem fins lucrativos que se dedica a defender a liberdade de expressão e de imprensa em todas as Américas. No entanto, conforme salienta o jornalista Paulo Cannabrava Filho, os seus integrantes confundem os conceitos de liberdade de expressão com os de livre empresa no marco do liberalismo econômico? ${ }^{7}$.

A verdadeira liberdade de expressão exige a integridade da notícia e a possibilidade de trânsito e discussão de ideias, o que não tem se verificado na imprensa atual, que tem se pautado por um discurso unilateral. É imprescindível que exista uma circulação das informações que suplante a realidade vigente, em que os grandes conglomerados que decidem aquilo que as pessoas devem ou não saber. As grandes maiorias também devem ter a possibilidade de se expressar através dos meios de comunicação.

Contudo, não é essa a preocupação dos grandes conglomerados midiáticos brasilieros e da SIP. Os discursos dessas organizações quanto à liberdade de expressão sempre estão vinculados a uma intensa preocupação em coibir qualquer regulamentação da imprensa. A possibilidade de um marco regulatório é sempre associada a atos de censura e violência, buscando-se contaminar qualquer discussão autêntica sobre o tema, de forma a impedir que os grandes conglomerados percam o monopólio da informação.

Em reportagem publica no Jornal O Globo em 7 de abril de 2014, estabeleceu-se nítida relação entre a morte do cinegrafista Santiago Andrade, da Rede Bandeirantes, ao ser atingido por um explosivo lançado por manifestantes na Central do Brasil, e a discussão de normas de regulação da mídia. Segundo o relatório elaborado pela SIP, citado na referida reportagem,

\footnotetext{
"é preocupante que muitos manifestantes aliem a agressividade contra os jornalistas a atitudes hostis à mídia empresarial, à reivindicação de que o governo proponha normas mais drásticas de regulação da mídia do que as já existentes e a uma vaga promoção de formas 'populares' de comunicação"8
}

$6 \quad$ CANNABRAVA FILHO, Paulo. SIP: Sociedade de Informação Privada. Disponível em: <http://www.cartamaior.com.br/?/Editoria/Internacional/SIP-Sociedade-da-Informacao-

Privada\%0D\%0A/6/26180>. Acesso em: 24 de março de 2014.

$7 \quad$ Idem.

$8 \quad \mathrm{O}$ GLOBO. Ameaça à Liberdade de Expressão Teve Avanço "Dramático" no País. 07 de abril de 2014. Disponível em: <http://oglobo.globo.com/sociedade/ameaca-liberdade-deexpressao-teve-avanco-dramatico-no-pais-12118007>. Acesso em 04 de julho de 2014. Outros exemplos de situações em que a liberdade de expressão foi invocada para impedir qualquer regulamentação da mídia podem ser encontrados em RODRIGUES, Diogo Moyses. O Direito Humano à Comunicação: Igualdade e Liberdade no Espaço Público Mediado por Tecnologias. Dissertação de Mestrado. Universidade de São Paulo, São Paulo, 2010. 
No Brasil, o Instituto de Estudos e Pesquisas em Comunicação - EPCOM concluiu em estudo sobre a concentração dos meios de comunicação em 2002, intitulado "Os Donos da Mídia", que Globo, SBT, Bandeirantes, Record, Rede TV! e CNT aglutinavam 668 veículos em todo o país, compostos por 309 canais de televisão, 308 canais de rádio e 50 jornais diários ${ }^{9}$.

O Grupo Globo, que cresceu à sombra da ditadura militar que prevaleceu no Brasil, é o maior símbolo da concentração da mídia no país. Além de deter cerca de $70 \%$ da audiência e $50 \%$ das verbas destinadas à publicidade ${ }^{10}$, é proprietária de revistas, portais de internet, emissoras de rádio e canais de TV por assinatura, uma estratégia de sucesso que solapa qualquer possibilidade de competição.

Além da concentração, a mídia brasileira também é marcada por estreitos laços com a política. Há muitos anos, as concessões de rádio e TV são usadas como moedas de barganha política, para compra de apoio dos parlamentares em medidas que são de interesse aos governantes.

Exemplo claro desse expediente ocorreu no Governo Sarney, quando o então presidente concedeu em apenas quatro anos 1.028 concessões de emissoras de rádio e TV, sendo que desse total ao menos 91 destinaram-se diretamente a deputados e senadores constituintes, que aprovaram a manutenção do regime presidencialista e a emenda que the garantiu cinco anos de mandato ${ }^{11}$.

O Decreto no 1.720/95 estabeleceu restrições às concessões, transmitindo a ideia de que estava começando uma fase moralizadora. Contudo, graças a uma brecha desse decreto que possibilitava que estações retransmissoras de televisão fossem distribuídas sem a necessidade de aprovação do Congresso, às vésperas da aprovação da emenda que permitiu a reeleição do presidente Fernando Henrique Cardoso, uma portaria do Ministério das Comunicações outorgou 1.848 licenças de RTV's, das quais ao menos 268 beneficiaram entidades ou empresas controladas por políticos ${ }^{12}$.

Estudiosos da área de comunicação também têm utilizado frequentemente o termo "coronelismo eletrônico" para se referir ao fenômeno pelo qual os chefes políticos oligárquicos

9 EGYPTO, Luiz. Quem são os Donos da Mídia no Brasil. Disponível em: <http://www.observatoriodaimprensa.com.br/cadernos/cid240420021.htm>. Acesso em $05 \mathrm{de}$ julho de 2014. Interessantes detalhamentos estaísticos quanto à concentração dos meios de comunicação em nosso país podem ser encontrados, ainda, no site <http://www.donosdamidia.com.br> e em VIEIRA JR., Vilson. Oligopólio na comunicação: um Brasil de poucos. Disponível em: <http://www.direitoacomunicacao.org.br/index2.php?option=com docman\&task=doc view\&gid= 342\&ltemid=99999999 $>$. Acesso em 06 de julho de 2014.

10 MATTOS, Sérgio. Um Perfil da TV Brasileira. Disponível em: <http://www.andi.org.br/sites/default/files/legislacao/02.\%20Um\%20perfil\%20da\%20TV\%20bras ileira.\%2040\%20anos\%20de\%20hist\%C3\%B3ria.pdf>. Acesso em 05 de julho de 2014.

$11 \quad$ LIMA, Venício Artur de; LOPES, Cristiano Aguiar. Coronelismo eletrônico de novo tipo (1999-2004) - as autorizações de emissoras como moeda de barganha política. Disponível em: <http://donosdamidia.com.br/media/documentos/Coronelismo.pdf>. Acesso em 07 de julho de 2014.

12 PIERANTI, Octavio Penna. Políticas para a Mídia: dos militares ao governo Lula. Lua Nova - Revista de Cultura e Política, São Paulo, nº 68, 2006, p. 108. 
utilizam estações geradores e retransmissoras da rádio e TV para influenciar a opinião pública e garantir sua perpetuação no poder.

As alíneas a e $b$ do inciso I do artigo 54 da Constituição Federal proíbem que deputados e senadores firmem contratos ou exerçam cargo, função ou emprego remunerado em empresas concessionárias de serviços públicos. O Código Brasileiro de Telecomunicações já contém disposição semelhante desde 1962, dispondo no parágrafo único do artigo 38, renumerado como parágrafo primeiro pela Medida Provisória № 648/2014, que aquele que estiver em gozo de imunidade parlamentar não pode exercer a função de diretor ou gerente de concessionária, permissionária ou autorizada de serviço de radiodifusão.

No entanto, diversas pesquisas realizadas sobre o tema têm demonstrado que essas normas não têm sido cumpridas. O projeto Donos da Mídia comparou os dados da Agência Nacional de Telecomunicações e a lista de prefeitos, governadores, deputados e senadores de todo o país para concluir que 271 políticos com mandatos que se estenderiam até o final de 2008 eram sócios ou diretores de 324 veículos de comunicação ${ }^{13}$. Essa lista é, certamente, ainda muito mais ampla, pois muitos políticos utilizam os nomes de parentes ou laranjas para escapar dessas regras restritivas.

A informação é um instrumento extremamente valioso durante o processo eleitoral, podendo ser um utilizada para a manipulação ou a democratização, conforme o modo como é direcionada. Justamente por esse motivo, a mídia foi paulatinamente reconhecida como uma instituição política, pois as sociedades somente podem se pretender efetivamente democráticas quando os cidadãos possuem informações fidedignas sobre os candidatos ${ }^{14}$.

Os especialistas tendem a acreditar que as pesquisas de opinião realizadas no curso dos processos eleitorais realmente possuem certo peso, especialmente sobre os votos dos indecisos. Todos já ouvimos falar que os eleitores menos politizados escolhem os candidatos mais fortes apenas para não perderem seus votos. Se a pesquisa é viciada, é evidente que pode galgar alguns votos para os candidatos que a manipularam e ainda lhes permitir estimular a militância ou conseguir maior espaço na mídia.

Em entrevista concedida ao site Carta Maior, o cientista político Francisco Fonseca, doutor em história social pela Universidade de São Paulo e professor da Fundação Getúlio Vargas, aponta como exemplo a Datafolha, que está diretamente vinculada à Folha de São Paulo. Ao entrevistar o diretor de redação, Otávio Frias Filho, para o seu livro "Consenso Forjado", este Ihe informou que a Folha de São Paulo era um jornal da classe média para a

13 Disponível em $\leq$ http://donosdamidia.com.br/levantamento/politicos $>$. Acesso em 06 de julho de 2014.

14 FONSECA, Francisco César Pinto da. Mídia e Democracia: falsas confluências. Disponível em $\leq$ http://www.scielo.br/pdf/rsocp/n22/n22a03.pdf>. Acesso em 12 de julho de 2014. 
classe média. Como a classe média possui uma opção política clara, ele alerta que é necessário olhar com bastante cautela os erros de pesquisas da Datafolha ${ }^{15}$.

\section{CAMINHOS PARA A DEMOCRATIZAÇÃO DOS MEIOS DE COMUNICAÇÃO}

A constatação de que a mídia brasileira é dominada por grandes oligopólios econômicos e desempenha um enorme poder sobre a sociedade, inclusive na eleição de seus governantes, suscita a reflexão acerca da necessidade de criação de um marco regulatório que garanta a sua democratização. Não se pretende defender com esse artigo nenhum tipo de censura ao conteúdo veiculado pelos meios de comunicação, mesmo porque os fatos podem ser interpretados sob diversas óticas, não havendo jamais a possibilidade de se encontrar uma neutralidade absoluta.

É essencial, contudo, notar que a notícia não é uma mercadoria como outra qualquer, que pode ser simplesmente articulada em conformidade com os interesses econômicos e privados que se encontram ocultos sobre os grandes conglomerados midiáticos. Trata-se de um serviço público, que é concedido aos particulares mediante concessões, mas que deve sempre ser permeado pelos interesses da sociedade.

O direito de informar foi tradicionalmente interpretado como uma liberdade negativa, que deveria ser protegida especialmente do Poder Público, que não poderia criar quaisquer óbices para a livre circulação de informações. Entretanto, essa concepção é insuficiente para garantir o intercâmbio de ideias na sociedade atual, em que apenas uma pequena parcela abastada da sociedade detém o controle dos meios de comunicação.

O Estado brasileiro deve atuar positivamente para afastar os obstáculos que se colocam ao livre acesso à informação, o que deve se concretizar, primeiramente, mediante a efetiva implementação do $\S 5^{\circ}$ do artigo 220 da Constituição Federal, que veda que os meios de comunicação sejam objeto, direta ou indiretamente, de monopólios ou oligopólios. Impedir-se-á, assim, que alguns pequenos grupos controlem os veículos de comunicação e escolham ao seu talante as matérias que merecem ser de conhecimento da população.

Em 10 de novembro de 2010, o Partido Socialismo e Liberdade - PSOL e a Confederação Nacional dos Trabalhadores em Comunicação e Publicidade - CONTCOP ingressaram com as Ações Diretas de Inconstitucionalidade por Omissão no 10 e 11, assistidos pelo jurista Fábio Konder Comparato, que estão tramitando em conjunto, nas quais postularam que a corte determine ao Congresso Nacional a regulamentação dos artigos 220, 221 e 223 da Constituição Federal, elaborando legislação específica sobre o direito de resposta, a proibição de monopólios ou oligopólios dos meios de comunicação e a produção e programação exibida pelos veículos.

O Congresso Nacional e a Advocacia Geral da União emitiram opiniões desfavoráveis à pretensão constante dessas ações. O Congresso Nacional argumentou que não há omissão

15 HARARI, Isabel; SERAFIM, Mailliw. A grande imprensa brasileira tem lado e classe social. Disponível em <http://www.cartamaior.com.br/?/Editoria/Primeiros-Passos/-A-grandeimprensa-brasileira-tem-lado-e-classe-social-\%0A/42/26246>. Acesso em 24 de março de 2014. 
inconstitucional na efetivação de tais determinações constitucionais e que existem projetos de lei em tramitação regulamentando os temas remanescentes. Já a AGU aduziu que a proibição do monopólio e oligopólio não dependem de regulamentação, já que a Constituição Ihes garante eficácia plena e imediata.

Contudo, no início de maio de 2012, a Procuradoria Geral da República manifestou-se favoravelmente às pretensões. Em parecer elaborado pela Vice-Procuradora-Geral da República Débora Macedo Duprat de Britto Pereira e aprovado pelo Procurador-Geral da República, o Ministério Público afirmou que se revela

"legítima a intervenção do Estado na estruturação e no funcionamento do mercado. Principalmente quando se trata de coibir os excessos de concentração de poderes em determinados grupos econômicos, de modo a se garantir a diversidade de pontos de vista e a prevalência da autonomia individual na livre formação de convicção de cada um"16.

Embora os autos encontrem-se conclusos com a relatora, Ministra Rosa Weber, até a atualidade, ainda sem previsão de data para julgamento, o ajuizamento de tais ações denota que importantes entidades têm se empenhado em colocar o tema em discussão, permitindo que seja criada uma legislação à semelhança daquelas que já existem em diversos outros países.

A necessidade de pluralismo dos meios de comunicação não é uma dificuldade enfrentada apenas em nosso país. O tema sempre esteve na pauta da União Europeia, merecendo destaque um relatório encomendado em outubro de 2011 com o objetivo de apresentar um conjunto de recomendações para a observância, a proteção, o apoio e a promoção do pluralismo e da liberdade da mídia na Europa.

O texto, concluído em janeiro de 2013 e intitulado "Um mídia livre e plural para apoiar a democracia europeia", foi objeto de análise pelo jornalista Venício Artur de Lima, que realçou a distinção estabelecida entre o pluralismo da mídia, que

"é um conceito que vai muito além da propriedade da mídia... contempla muitos aspectos, das regras para controle de fusões, por exemplo, até exigências de conteúdo para concessões de sistemas de radiodifusão, estabelecimento de liberdade editorial, independência e status dos veículos de radiodifusão, situação profissional dos jornalistas, relacionamento entre a mídia e os atores políticos etc.

16 O parecer integral emitido pela Procuradoria-Geral da República está disponível em <http://artigo.19.org/centro/casos/detail/16>. Acesso em 11 de julho de 2014. 


\begin{abstract}
Abarca todas as medidas que garantam acesso dos cidadãos a uma variedade de fontes de informações e vozes, para permitir que eles possam formar opiniões isentas de influências indevidas de um poder dominante formador de opinião."17
\end{abstract}

No âmbito latinoamericano, deve ser objeto de estudo a Lei oㅜ 26.522, aprovada pela ampla maioria do parlamento argentino em outubro de 2009 e intitulada Lei de Serviços de Comunicação Audiovisual, que regulamenta, dentre outras matérias, a propriedade dos meios de comunicação. Merecem destaque o artigo 41, que torna as licenças intransferíveis, o 45, que estabelece que uma mesma empresa pode ter no máximo $35 \%$ do mercado a nível nacional e 24 licenças, o 48, que acaba com o direito adquirido para as empresas que possuem mais concessões, e o 161, que concede o prazo de um ano para as empresas se adequarem à lei.

O Grupo Clarín, maior conglomerado de meios de comunicação da Argentina, com 240 licenças, $41 \%$ do mercado de rádio, $38 \%$ da TV aberta e $59 \%$ da TV a cabo ${ }^{18}$, questionou judicialmente a constitucionalmente de tais artigos, argumentando que violariam seu direito de propriedade.

No curso desse embate, surgiram diversos artigos sustentando que a iniciativa seria um reflexo do caráter autoritário da presidente Cristina Kirchner, compondo um plano para desestruturação do Grupo Clarín, pelo fato de adotar uma linha editorial de oposição. A Sociedade Interamericana de Imprensa chegou inclusive a aprovar o envio de uma missão internacional com o intuito de impedir que o governo perseguisse e intimidasse a mídia e os jornalistas ${ }^{19}$

Em sentido diametralmente oposto, o Relator Especial da ONU sobre Liberdade de Expressão e Opinião, Frank La Rue, elogiou a legislação aprovada pela Argentina, salientando que resultou de uma discussão democrática, equilibrando equitativamente os interesses comerciais, comunitários e públicos presentes no setor audiovisual, promovendo a diversidade dos meios de comunicação e o pluralismo de ideias e tratando-se de um modelo para todo o continente e outras regiões do mundo 20 .

17 LIMA, Venício Artur de. Três documentos, uma diretriz. Disponível em: <http://www.observatoriodaimprensa.com.br/news/imprimir/59091>. Acesso em 11 de julho de 2014.

18 SEVERO, Leonardo Wexell; SILVA, Vanessa. Sócio do Clarín quer adequação à lei de meios. Disponível em: <http://www.cartamaior.com.br/?/Editoria/Internacional/Socio-do-Clarinquer-adequacao-a-lei-de-meios/6/26343>. Acesso em 24 de março de 2014.

$19 \quad$ As conclusões das assembleias realizadas pela Sociedade Interamericada de Imprensa sobre a Lei de Meios argentina encontram-se disponíveis em: <http://www.sipiapa.org/ptbr/asamblea/argentina-ii-36> e http://www.sipiapa.org/pt-br/asamblea/argentina-48/>. Acesso em 12 de julho de 2014.

20 CARTA MAIOR. Ley de Medios argentina é modelo, diz relator da ONU. Disponível em: $\leq$ http://www.cartamaior.com.br/?/Editoria/Internacional/Ley-de-Medios-argentina-e-modelo-dizrelator-da-ONU\%0D\%0A/6/26192 >. Acesso em 24 de março de 2014. Ao comparecer ao Brasil entre 11 e 15 de dezembro de 2012 a convite do Fórum Nacional pela Democratização da Comunicação (FNDC), o relator defendeu esse mesmo posicionamento. Disponível

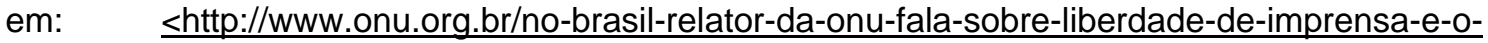


Mediante sucessivas medidas liminares, o Grupo Clarín conseguiu suspender a aplicação dessa lei por quase quatro anos, até que, no final de outubro de 2013, a Suprema Corte daquele país declarou a lei constitucional, por ser coerente com a liberdade de expressão e o direito dos consumidores à informação ${ }^{21}$. Em novembro, o grupo apresentou um plano para se adequar à lei, que foi aprovado pela Autoridade Federal de Serviços de Comunicação Audiovisual (Afsca), sendo concedido um prazo de seis meses para sua finalização, que se encerrou justamente em agosto de 2014.

A experiência ocorrida na Argentina denota o atraso do Brasil na regulamentação das concentrações dos meios de comunicação, mas também evidencia que é possível centralizar o debate na efetiva democratização dos meios de comunicação, suplantando os inflados discursos dos grandes conglomerados midiáticos de que qualquer tipo de regulamentação implicaria retorno à censura.

Não basta, contudo, que o Estado coiba os óbices à livre circulação da informação criados pelos oligopólios econômicos e grupos políticos dententores dos meios de comunicação. É imprescindível que promova mecanismos que garantam que o direito de informar seja exercido em conformidade com os princípios albergados no artigo 221 da Constituição Federal, que privilegiam as finalidades educativas, artísticas, culturais e informativas, a promoção da cultura nacional e regional, o estímulo da produção independente que objetive a sua divulgação, a regionalização da produção cultural, artística e jornalística e o respeito aos valores éticos e sociais da pessoa e da família.

Esse não é, obviamente, o quadro que se observa nos meios de comunicação de nosso país, dominados por programas estrangeiros ou notícias sensacionalistas e apelativas, com o primordial objetivo de garantir altos índices de audiência. O jornalista André Nunes Ricardo Martins realiza uma interessante crítica dos discursos utilizados pela mídia para se referir às minorias, demonstrando que prevalecem versões reducionistas e jocosas, centradas nos incômodos e nos benefícios concedidos a esses grupos, sem refletir sobre suas especificidades culturais e históricas ${ }^{22}$.

Uma medida que pode contribuir para o equacionamento desse problema é a criação de uma regulamentação que estabeleça critérios impessoais para as outorgas e renovações de concessões aos veículos de radiodifusão, que condicionem o seu deferimento ao potencial do candidato em promover a concretização dos princípios albergados pela Constituição Federal.

papel-do-jornalismo-critica-acao-no-stf-e-elogia-ley-de-medios/>. Acesso em 12 de julho de 2014.

21 LA NACIÓN. La Corte Suprema declaró constitucional la ley de medios. Disponível em: shttp://www.lanacion.com.ar/1633615-la-corte-suprema-declaro-constitucional-la-ley-demeios>. Acesso em 12 de julho de 2014.

22 MARTINS, André Ricardo Nunes. Grupos excluídos no discurso da mídia: uma análise de discurso crítica. Disponível em: $\leq$ http://www.scielo.br/scielo.php?script=sci arttext\&pid=S0102-

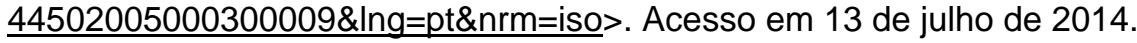


Essa é uma das propostas constantes da campanha "Para Expressar a Liberdade uma nova lei para um novo tempo" 23 , que salienta, ainda, a necessidade de ampla publicidade de tais critérios e do andamento dos requerimentos e do acompanhamento permanente do cumprimento das obrigações, inclusive com a possibilidade de revogação da concessão caso constatado seu desvirtuamento.

Embora a Constituição Federal de 1988 tenha imposto que sua outorga e renovação devem ser necessariamente submetidas ao crivo do Congresso Nacional, não se tratando mais de ato exclusivo do Poder Executivo, as concessões ainda são objeto de fortes influências políticas. A fixação de critérios objetivos e a ampla publicidade dos requerimentos seria útil, ainda, para resolver essa questão, evitando que as concessões continuem a ser usadas como moedas de troca de favores políticos.

A própria lei fundamental estabelece em seu artigo 223 um outro caminho para garantir a concretização de tais princípios, ao dispor que as concessões de serviços de radiodifusão sonora e de sons e imagens devem privilegiar a pluralidade informativa e cultural mediante a complementaridade entre os sistemas privado, público e estatal.

O sistema público compreende as iniciativas empreendidas pela sociedade organizada na área das comunicações, com possibilidade de atuação de coletividades, seja em um determinado âmbito territorial, como um bairro ou uma região, seja em um grupo que detém identidade de afinidades, como mulheres ou negros ${ }^{24}$. Abrange as emissoras comunitárias e universitárias, além de outras organizações que produzem comunicação com o objetivo de promoção do interesse público, desde que não estejam submetidas ao controle estatal e sequer ao viés lucrativo da mídia privada.

Na Argentina, a já citada Lei de Serviços de Comunicação Audiovisual garantiu ao menos um terço das concessões às organizações privadas sem fins lucrativas, em igualdade de condições com as emissoras estatais e as privadas. Com espeque nesse dispositivo, foram concedidas dezenas de autorizações a universidades e escolas receberam autorizações para criarem emissoras de rádio e TV, sendo criado no final de 2012 o primeiro canal de televisão índigena do país, oferecendo aos povos originários uma oportunidade para difusão de sua cultura $^{25}$.

O Brasil, em posição absolutamente distinta, tem coibido violentamente as rádios comunitárias, que são taxadas pela mídia comercial como trangressoras da lei, sendo inclusive responsáveis pela queda de aviões. O juiz federal aposentado Paulo Fernando Silveira aponta em entrevista concedida ao Observatório de Imprensa que esse argumento é uma falácia, uma

23 Essa campanha é resultado da mobilização de dezenas de entidades da sociedade civil que se reuniram em São Paulo, no dia 04 de maio de 2012, no Seminário Desafios da Liberdade de Expressão, promovido pelo Fórum Nacional pela Democratização da Comunicação - FNDC. Disponível em: <http://paraexpressaraliberdade.org.br/>. Acesso em 13 de julho de 2014.

24 CABRAL FILHO, Adilson Vaz. Sistema, comunicação, TVs...: o público excluído das definições sobre si mesmo!. Disponível em: <http://www.comunicacao.pro,br/setepontos/39/spc.htm>. Acesso em 13 de julho de 2014. 25 LEAL FILHO, Laurindo Lalo. Argentina e os ganhos da liberdade de expressão. Disponível em: <http://redebrasilatual.com.br/revistas/89/ganhos-da-liberdade-de-expressao9472.html>. Acesso em 13 de julho de 2014. 
vez que as rádios comerciais, que possuem inclusive uma potência muito superior, também podem interferir nas frequências utilizadas pelas torres dos aeroportos ${ }^{26}$.

Conforme ressaltado pelo magistrado, em passagem que se aplica a todos os veículos de comunicação, os cidadãos possuem o direito de se comunicarem, não cabendo ao governo decidir se autoriza ou não o exercício desse direito fundamental. O papel do Estado é meramente administrativo, a quem compete conciliar o uso do espectro eletromagnético, de forma que todos possam usufruir regularmente esse direito, sem interferir em seu gozo pelos demais ${ }^{27}$.

\section{CONCLUSÃO}

O período de ditadura militar deixou profundas e dolorosas recordações em nosso país, especialmente em razão da exacerbada censura aos meios de comunicação, subjugados brutalmente aos interesses do governo ditatorial sempre que manifestassem qualquer posição dissonante do regime. Não é à toa, portanto, que a liberdade de imprensa, conquistada a tão duras penas, seja valorizada e respeitada como direito essencial do ser humano.

Contudo, os grilhões que amordaçavam os jornalistas não foram suprimidos na sociedade atual, mas sim substituídos por grandes oligopólios que concentram em suas mãos 0 controle dos meios de comunicação e, sob o falso argumento de proteção dessa liberdade, decidem de acordo com seus interesses os fatos que podem e não podem ser conhecidos pelos telespectadores.

É imprescindível que a sociedade tome consciência que os veículos que exploram comercialmente a mídia não são proprietários das concessões públicas, exercendo suas atividades apenas e enquanto sua atuação também favorecer a concretização do interesse público e a efetivação dos princípios traçados pela Constituição Federal.

No momento em que essa concepção tornar-se clara, será fácil compreender a urgência da criação de um marco regulatório que garanta a democratização dos meios de comunicação, possibilitando a efetiva pluralidade de ideias e o intercâmbio de informações, de modo a fornecer aos cidadãos a possibilidade de formarem suas opiniões livremente.

Obviamente, a efetivação do direito à comunicação não será a solução para todos os problemas que assolam o Brasil. Mas não há dúvidas de que os cidadãos somente poderão contribuir efetivamente para a democracia, escolhendo seus governantes de forma conscientee responsável, quando tiverem acesso a informações fidedignas e desvinculadas de interesses políticos e econômicos.

26 COSTA, Júlia; GASPAR, Júlia. “Rádio comunitária é transferência de poder”. Disponível em: <http://www.observatoriodaimprensa.com.br/news/view/radio comunitaria e transferencia de poder>. Acesso em 14 de julho de 2014. 27 Idem. 
Conforme salientou o jurista Celso Antônio Bandeira de Mello no seminário "Democracia Digital e Poder Judiciário", em reflexão que resume bem o assunto, as liberdades de expressão e comunicação devem privilegiar o direito do cidadão a conhecer aquilo que ocorre a sua volta, e não o interesse dos empresários em obterem lucros com a difusão das informações ${ }^{28}$.

\section{REFERÊNCIAS}

BOBBIO, Norberto. A Era dos Direitos. Rio de Janeiro: Editora Elsevier, 2004.

CABRAL FILHO, Adilson Vaz. Sistema, comunicação, TVs...: o público excluído das definições sobre si mesmo!. Disponível em: <http://www.comunicacao.pro,br/setepontos/39/spc.htm>. Acesso em 13 de julho de 2014.

CANNABRAVA FILHO, Paulo. SIP: Sociedade de Informação Privada. Disponível em: <http://www.cartamaior.com.br/?/Editoria/Internacional/SIP-Sociedade-da-InformacaoPrivada\%0D\%0A/6/26180>. Acesso em: 24 de março de 2014.

CARTA MAIOR. Ley de Medios argentina é modelo, diz relator da ONU. Disponível em: <http://www.cartamaior.com.br/?/Editoria/Internacional/Ley-de-Medios-argentina-e-modelo-dizrelator-da-ONU\%0D\%0A/6/26192>. Acesso em 24 de março de 2014.

CHAUÍ, Marilena. Poder da Mídia. Disponível em: <http://www.paraexpressaraliberdade.org.br/index.php/noticias/80-chaui-integral>. Acesso em: 04 de julho de 2014.

COSTA, Júlia; GASPAR, Júlia. "Rádio comunitária é transferência de poder". Disponível em: $\leq$ http://www.observatoriodaimprensa.com.br/news/view/radio comunitaria e transferencia de poder>. Acesso em 14 de julho de 2014.

EGYPTO, Luiz. Quem são os Donos da Mídia no Brasil. Disponível em: <http://www.observatoriodaimprensa.com.br/cadernos/cid240420021.htm>. Acesso em $05 \mathrm{de}$ julho de 2014.

FARIAS, Edilsom Pereira de. Liberdade de Expressão e Comunicação: Teoria e proteção constitucional. Tese de Doutorado. Universidade Federal de Santa Catarina, Florianópolis, 2001.

FONSECA, Francisco César Pinto da. Mídia e Democracia: falsas confluências. Disponível em <http://www.scielo.br/pdf/rsocp/n22/n22a03.pdf >. Acesso em 12 de julho de 2014.

HARARI, Isabel; SERAFIM, Mailliw. A grande imprensa brasileira tem lado e classe social. Disponível em_http://www.cartamaior.com.br/?/Editoria/Primeiros-Passos/-A-grande-imprensabrasileira-tem-lado-e-classe-social-\%0A/42/26246>. Acesso em 24 de março de 2014.

LA NACIÓN. La Corte Suprema declaró constitucional la ley de medios. Disponível em: <http://www.lanacion.com.ar/1633615-la-corte-suprema-declaro-constitucional-la-ley-demeios $>$. Acesso em 12 de julho de 2014.

NASSIF, Lourdes. Para Bandeira de Mello, liberdade de imprensa não é para fins capitalistas. Disponível em: shttp://jornalggn.com.br/noticia/para-bandeira-de-mello-liberdade-de-imprensanao-e-para-fins-capitalistas. $\geq$. Acesso em 25 de março de 2014. 
LEAL FILHO, Laurindo Lalo. Argentina e os ganhos da liberdade de expressão. Disponível em: <http://www.redebrasilatual.com.br/revistas/89/ganhos-da-liberdade-de-expressao-9472.html >. Acesso em 13 de julho de 2014.

LIMA, Venício Artur de. Três documentos, uma diretriz. Disponível em: <http://www.observatoriodaimprensa.com.br/news/imprimir/59091>. Acesso em 11 de julho de $\underline{2014 .}$.

LIMA, Venício Artur de; LOPES, Cristiano Aguiar. Coronelismo eletrônico de novo tipo (19992004) - as autorizações de emissoras como moeda de barganha política. Disponível em: <http://donosdamidia.com.br/media/documentos/Coronelismo.pdf>. Acesso em $07 \mathrm{de}$ julho de 2014.

MARTINS, André Ricardo Nunes. Grupos excluídos no discurso da mídia: uma análise de discurso crítica. Disponível em: <http://www.scielo.br/scielo.php?script=sci arttext\&pid=S0102$44502005000300009 \&$ lng=pt\&nrm=iso $>$. Acesso em 13 de julho de 2014.

MATTELART, Armand. A Construção Social do Direito à Comunicação como parte integrante dos Direitos Humanos. Intercom - Revista Brasileira de Ciências da Comunicação, São Paulo, v. 32, no I, jan./jun. de 2009, p. 33-50.

MATTOS, Sérgio. Um Perfil da TV Brasileira. Disponível em: <http://www.andi.org.br/sites/default/files/legislacao/02.\%20Um\%20perfil\%20da\%20TV\%20bras ileira.\%2040\%20anos\%20de\%20hist\%C3\%B3ria.pdf>. Acesso em 05 de julho de 2014.

NOVELLI, Pedro Geraldo Aparecido. A Questão da Liberdade de Expressão em Hegel. Disponível em: <http://www.uece.br/kalagatos/dmdocuments/A-questao-da-liberdade-deexpressao-em-Hegel.pdf>. Acesso em 02 de julho de 2014.

O GLOBO. Ameaça à Liberdade de Expressão Teve Avanço "Dramático" no País. 07 de abril de 2014. Disponível em: <http://oglobo.com/sociedade/ameaca-liberdade-de-expressao-teveavanco-dramatico-no-pais-12118007>. Acesso em 04 de julho de 2014.

PIERANTI, Octavio Penna. Políticas para a Mídia: dos militares ao governo Lula. Lua Nova Revista de Cultura e Política, São Paulo, ํㅡ 68, 2006, p. 91-122.

RODRIGUES, Diogo Moyses. O Direito Humano à Comunicação: Igualdade e Liberdade no Espaço Público Mediado por Tecnologias. Dissertação de Mestrado. Universidade de São Paulo, São Paulo, 2010.

SEVERO, Leonardo Wexell; SILVA, Vanessa. Sócio do Clarín quer adequação à lei de meios. Disponível em: shttp://www.cartamaior.com.br/?/Editoria/Internacional/Socio-do-Clarin-queradequacao-a-lei-de-meios/6/26343>. Acesso em 24 de março de 2014.

VIEIRA JR., Vilson. Oligopólio na comunicação: um Brasil de poucos. Disponível em: <http://www.direitoacomunicacao.org.br/index2.php?option=com docman\&task=doc view\&gid= 342\&ltemid=99999999 $>$. Acesso em 06 de julho de 2014. 